\title{
The Demand for Gold by the Electronics Industry in Europe
}

\author{
Tim Cooke \\ International Gold Corporation, Johannesburg, South Africa
}

\begin{abstract}
Some data on the demand for gold in the electronics and decorative industries appeared in an earlier issue of this Bulletin (1). The present article updates the 1982 estimates of consumption and reviews some of the developments which bave since occurred in Europe.
\end{abstract}

World-wide usage of gold for electronics and decorative applications amounted to 181 tons in 1984 and 167 tons in 1985 (2), equivalent to $12.3 \%$ and $11.3 \%$ respectively, of the total amount of gold fabricated in those years. The personal computer inventory build-up in 1984, and the subsequent depression in sales in that segment, was largely responsible for the lower gold usage in 1985.

Attempting to analyse gold usage in detail in the electronic and decorative industries has not been without difficulties. The method used was similar to that of the previous study: first, major manufacturers and gold producers in each market were identified. Knowledgeable people in each country were then asked for their estimates of the national consumption of gold by the particular segments of the industry with which they were concerned. This procedure avoided the respondents having to reveal confidential company information and also provided a check on the consistency of market estimates. There was good overall agreement between the various estimates of market size within each country.

The levels of consumption recorded in this article are therefore not precise quantities but estimates by leading and wellinformed processors and users of gold.

In 1983 and 1985 the consumption of gold in Western Europe for electronic applications emerged as 24 tons (3), or approximately $22 \%$ of total world fabrication. This is marginally less than the 26 tons for 1980 . The forecast for 1986 is 23 tons.

The fall in consumption between 1980 to 1983 was a direct result of the very high gold prices. The steady demand from 1983 to 1985 was due to an expanding electronics production and a more stable gold price, while the expected fall from 1985 to 1986 is caused by declining electronics production associated with a post-boom depression in microcomputer sales.

Plating absorbed $66 \%$ of the gold used in electronics 15.8 tons out of the 23.9 tons. Table I (3) shows the breakdown by application in 1985 .

Germany constituted the largest market, accounting for about $37 \%$ ( 9 tons) of the total gold consumption (5). The U.K. consumed $14 \%$ ( \pm 4 tons) and France and the Benelux countries about 3 tons each.

The relative amounts of gold used in the production of different types of products $(5,3)$ in 1983 and 1985 are set out in Table II.

\section{Connectors}

The production of connectors absorbed half of the total gold used in electronics in 1985 . The 1986 estimates indicate a slight increase to $51 \%$. Gold provides the best reliability in general purpose connectors having a wide range of applications. Gold plating and gold inlays are used extensively in this industry. which, because of high cost, has become very concerned with economy. Although palladium-based alloy coatings have been introduced by some manufacturers for use in specific applications, the use of a gold flash surface finish to these coatings has been found desirable in very many instances.

The cost of gold as a proportion of connector production cost is estimated to be between $20 \%$ and $30 \%$ and is falling. In 1979 , it was about 33\%. It would appear, however, as if prospects for increasing use of gold are now favourable. Evidence for this came from seven connector manufacturing firms which were contacted on their expected use of gold over the next 5 years. All but one of them expected a steady or increasing use of gold. This indicates that limits may already have been reached in economising on the use of gold on connectors, and also that there is an air of optimism in the electronics industry for increased production in the years ahead.

Geográphically, the most important markets for gold for use in the production of connectors in Europe are Germany, ( 4.25 tons); U.K., ( \pm 2 tons); France, (1.5 tons) and Benelux ( 2 tons) of gold.

Most of the research and development work for connectors is still carried out in the U.S., however, and much of European production of general purpose connectors is to American standards.

The main markets for connectors are shown in Table III (5). 


\section{Printed Circuit Boards}

Most of the demand for printed circuits comes from computers and office machines, telecommunications and consumer electronics. The first two mentioned industries require high quality plating where gold is often specified.

There has been a steady decline in the amount of gold consumed by the printed circuit industry. The actual quantities are: 5.5 tons in 1980 (representing $22 \%$ of the gold consumed by electronics in Western Europe during that year): 4.5 tons (19\%) in 1983; and an expected 4 tons (17\%) in 1986.

The reasons for this decline are:

- the large amount of gold used in printed circuits produced in the U.K. during 1980. This was due to a telecommunications standard, requiring a 5 micron thickness film, which has since been changed.

- selective plating was introduced and adopted.

- with the increase in sophistication, fewer boards are now needed in a particular application.

\section{Semiconductor devices, switches, relays, and hybrid cir- cuits of thick and thin films}

$\square$ Integrated circuits. Included in this category are microprocessors and memory circuits for the computer, telecommunications and video games industries, and for applications in nearly every field of electronics.

Pure gold is used in several stages in the manufacture of integrated circuits, for example:

- plating the lead frame, into which the chip is soldered;

- coating the chip to improve solderability;

- coating ceramic packaging.

- connecting the many sections of the chip to the leads of the lead frame by ultra fine wires (bonding wires);

Whilst some manufacturers are investigating the use of palladium, aluminium or silicon-aluminium alloys for bonding wires, most manufacturers are still using gold, and are reluctant to use other metals. The consumption of gold in this application in Western Europe was estimated at about 0.5 tons in 1983 , and 0.7 tons in 1985.

Much investment, particularly from America, has gone into the Far East over the last two decades because of lower labour costs. However, as the cost of labour is increasing in the Far East, and as automated manufacturing methods are adopted, some producers are moving their production centres to areas nearer to the European market. For instance, several large American firms have established plants in Scotland.
TABLE I

Estimated demand for gold for various applications in the electronics industry in Europe in 1985.

Figures are in metric tons of fine gold

Plating

Wrought products

Evaporation wire

Bonding wires

Soft solder alloys and

brazing alloys

Thick film pastes

Sputtering targets

Other uses

Total

\begin{tabular}{|c|c|c|}
\hline $\begin{array}{l}\text { The use o } \\
\text { by the Eur }\end{array}$ & $\begin{array}{l}\text { roduct } \\
\text { industr }\end{array}$ & \\
\hline Figures : & e gold & \\
\hline & 1983 & 1985 \\
\hline Connectors & 10.8 & 12.1 \\
\hline Printed Circuits & 4.4 & 4.4 \\
\hline Semiconductors & 4.0 & 3.2 \\
\hline Switches and Relays & 2.2 & 2.7 \\
\hline Thick Films & 0.6 & 0.8 \\
\hline Thin Films/Other & & 0.7 \\
\hline Total & 24.0 & 23.9 \\
\hline${ }^{\star}$ not available & & \\
\hline
\end{tabular}

\begin{tabular}{|c|c|c|}
\hline \multicolumn{3}{|c|}{$\begin{array}{c}\text { TABLE III } \\
\text { Western European connector markets }\end{array}$} \\
\hline & $\begin{array}{l}1983 \\
\text { \$ mill. }\end{array}$ & $\begin{array}{c}1988 \text { (est) } \\
\$ \text { mill. }\end{array}$ \\
\hline Communications equipment & 418 & 965 \\
\hline Military equipment & 369 & 795 \\
\hline Computers & 241 & 687 \\
\hline Industrial electronics & 89 & 205 \\
\hline Instruments & 80 & 145 \\
\hline Consumer electronics & 77 & 130 \\
\hline $\begin{array}{l}\text { Office equipment and retail } \\
\text { electronics }\end{array}$ & 34 & 74 \\
\hline Automotive & 17 & 67 \\
\hline Total & 1325 & 3068 \\
\hline
\end{tabular}


$\square$ Discrete devices. These include transistors, diodes, thyristors and triacs. Gold is used in plating molybdenum discs used for power rectifiers and the cases of some high quality devices are also plated. Gold-tin alloy, in the proportion 80:20, is used as a high melting-point solder in the manufacture of power semiconductors. For lower power transistors, gold bonding wires are used.

$\square$ Switches and relays. Gold is still needed in switching devices where it is used in both plated and wrought form (inlays, strips, rivets etc.). The European market for switches and relays was 2.8 tons in 1984 compared with 2.2 tons in 1983 . The telecommunications industry is the most important user, where reed relays and switches are an important application. However, with the change towards all-electronic telecommunications systems, where the function of switches is carried out by semiconductor devices, there will be a substantial decline in the use of reed relays, and hence of gold.

$\square$ Hybrid circuits using thick and thin films absorbed nearly 2 tons of gold in 1985. In thick film circuits, a new process called the 'thin gold' process enables a $5 \mu \mathrm{m}$. thick layer to be deposited, as opposed to the previous minimum of 18 microns. This enables gold to be deposited over a much wider area, at lower cost. With thin film circuits, vacuum sputtering has the advantage of less gold wastage than the vacuum evaporation method. Gold represents $10-15 \%$ of the cost of a typical hybrid circuit. The market for thick film pastes is growing rapidly, gold used in thick film pastes was:

$550 \mathrm{~kg}$ in 1983

$640 \mathrm{~kg}$ in 1984

$840 \mathrm{~kg}$ in 1985

It was reported earlier (1) that substitution of gold by other metals in order to reduce costs was a factor in the overall decline in the use of gold in the electronics industry. Substitution is still possible but is becoming less attractive from the economic point of view. For example, the price of palladium has risen to over $\$ 100$ per ounce. (It was as low as $\$ 60$ an ounce in 1982.) Increasing efficiency in the use of gold and recovery of the metal from scrap has also helped in this connection. Most major users and suppliers of gold products have refining facilities and even smaller quantities of gold are being economically recovered by the use of new refining equipment. However, at present, the major factors in gold consumption are the levels of production of the various products.

It is interesting that, far from attempting to eliminate the use of gold, some manufacturers are now promoting their products by specific mention of the use of gold, and its advantages, in their advertisements.

Acknowledgements: The author thanks the various Managers and Consultants, in particular Mr. C.G. Wedgewood, for collating and compiling the data used in this article. It should be noted that many of the data used from the reports cited originate from other sources which are not listed. In such instances, the primary source is gratefully acknowledged.

\section{References}

1 T.D. Cooke, 'The demand for gold by industry', Gold Bulletin, 1982, 15, (2) $38-42$

2 Consolidated Gold Fields P.L.C., 'Gold 1986', May 1986

3 C.G. Wedgewood, 'The consumption of gold products by the West European electronics and electrical industries', Jan 1986, Confidential report to Intergold
4 C.G. Wedgewood, 'The consumption of gold products by the West European electronics and electrical industries', July 1985, Confidential report to Intergold

5 C.G. Wedgewood, 'The market and applications for gold and its derivatives in the West European electronics and electrical industries', April 1984 , Confidential report to Intergold. 